\title{
Industrial-scale production and purification of a heterologous protein in Lactococcus lactis using the nisin-controlled gene expression system NICE: The case of lysostaphin
}

\author{
Igor Mierau*1, Peter Leij ${ }^{1}$, Iris van Swam ${ }^{1}$, Barry Blommestein ${ }^{1}$, Esther Floris ${ }^{1}$, \\ James Mond ${ }^{2}$ and Eddy J Smid ${ }^{1}$
}

Address: ${ }^{1}$ NIZO food research, P.O. Box 20, 6710 BA Ede, The Netherlands and ${ }^{2}$ Biosynexus, Inc., 9119 Gaither Road, Gaithersburg, MD 20877, USA

Email: Igor Mierau* - igor.mierau@nizo.nl; Peter Leij - peter.leij@nizo.nl; Iris van Swam - iris.van.swam@nizo.nl;

Barry Blommestein - barry.blommestein@nizo.nl; Esther Floris - esther.floris@nizo.nl; James Mond - jimmymond@biosynexus.com; Eddy J Smid - eddy.smid@nizo.nl

* Corresponding author

Published: 27 May 2005

Microbial Cell Factories 2005, 4:15 doi:10.1 186/1475-2859-4-15
Received: 18 April 2005

Accepted: 27 May 2005

This article is available from: http://www.microbialcellfactories.com/content/4/1/15

(C) 2005 Mierau et al; licensee BioMed Central Ltd.

This is an Open Access article distributed under the terms of the Creative Commons Attribution License (http://creativecommons.org/licenses/by/2.0), which permits unrestricted use, distribution, and reproduction in any medium, provided the original work is properly cited.

\begin{abstract}
Background: The NIsin-Controlled gene Expression system NICE of Lactococcus lactis is one of the most widespread used expression systems of Gram-positive bacteria. It is used in more than 100 laboratories for laboratory-scale gene expression experiments. However, L. lactis is also a micro-organism with a large biotechnological potential. Therefore, the aim of this study was to test whether protein production in L. lactis using the NICE system can also effectively be performed at the industrial-scale of fermentation.

Results: Lysostaphin, an antibacterial protein (mainly against Staphylococcus aureus) from S. simulans biovar. Staphylolyticus, was used as a model system. Food-grade lysostaphin expression constructs in L. lactis were grown at IL-, 300-L and 3000-L scale and induced with nisin for lysostaphin production. The induction process was equally effective at all scales and yields of about $100 \mathrm{mg} / \mathrm{L}$ were obtained. Up-scaling was easy and required no specific effort. Furthermore, we describe a simple and effective way of downstream processing to obtain a highly purified lysostaphin, which has been used for clinical phase I trials.

Conclusion: This is the first example that shows that nisin-regulated gene expression in L. lactis can be used at industrial scale to produce large amounts of a target protein, such as lysostaphin. Downstream processing was simple and in a few steps produced a highly purified and active enzyme.
\end{abstract}

\section{Background}

Lactococcus lactis is a Gram-positive bacterium that is widely used in food production such as cheese and butter manufacturing [1]. In the last two decades the physiology and genetics of this bacterium have been thoroughly char- acterized [2]. At present several genomes are either completely sequenced or close to completion $[3,4]$. Furthermore, L. lactis is easily genetically accessible and a wide variety of genetic tools have been developed [5]. Because of the genetic accessibility and the ease of its 
Table I: Strains and Plasmids

\begin{tabular}{|c|c|c|}
\hline Bacterial strain/plasmid & Properties & Reference \\
\hline \multicolumn{3}{|l|}{ Bacteria } \\
\hline Lactococcus lactis subsp. cremoris NZ3900 & $\begin{array}{l}\text { Integration of nisRnisK in the chromosome; integration of the lac operon in the } \\
\text { in the chromosome and deletion of lacF resulting in a lactose- negative host } \\
\text { strain that can be complemented by lacF }\end{array}$ & {$[25]$} \\
\hline \multicolumn{3}{|l|}{ Plasmids } \\
\hline $\mathrm{pNZ8|} 48$ & $\begin{array}{l}\mathrm{P}_{\text {nisA }}, \mathrm{Cm}^{\mathrm{R}} \text {; replicon of rolling circle plasmid } \mathrm{pSH} 7 \mathrm{I} \text {, basic NICE vector, } \\
\text { derivative of } \mathrm{pNZ8048}\end{array}$ & {$[12][26]$} \\
\hline pNZI709 & Lysostaphin gene under control of $\mathrm{P}_{\text {nisA }}, \mathrm{Cm}^{\mathrm{R}}$; derivative of $\mathrm{pNZ8|} 48$ & This work \\
\hline pNZI7IO & $\begin{array}{l}\text { Lysostaphin gene under control of } \mathrm{P}_{\text {nisA }} \text {, lacF; expression vector for food- grade } \\
\text { expression, selection on growth with lactose; derivative of pNZI709 }\end{array}$ & This work [II] \\
\hline
\end{tabular}

handling, a variety of new applications have been developed. Examples are the expression of cytokines and bacterial or viral antigens [6,7], enzymes [8], membrane proteins [9] and metabolic transformations [10]. These studies show that $L$. lactis is a suitable host for applications beyond its traditional use in food fermentations.

One of the crucial developments has been the construction of a food grade [11] and regulated gene expression system based on the regulation mechanism of the nisin $\mathrm{A}$ operon of L. lactis. In this operon the gene product nisin (a 34 amino acid bacteriocin) activates its own transcription at $\mathrm{ng} / \mathrm{ml}$ amounts [12]. The elements of this regulatory system have been isolated and inserted in a suitable host strain, constituting the powerful regulated gene expression system NICE (NIsin-Controlled gene Expression system) $[5,13]$. The NICE system is widely used on laboratory scale for research and for over-expression of genes of interest $[8,9,14]$. However, experience in large scale application and fermentation of the NICE system is very limited.

Lysostaphin is a $25-\mathrm{kD}$ antibacterial protein, produced by Staphylococcus simulans biovar. Staphylolyticus, that can hydrolyze the Gly-Gly bonds in the cell wall of the pathogens $S$. aureus and S. epidermidis and thus lyse these bacteria $[15,16]$. Lysostaphin has been proven to be an effective agent against the widespread hospital infectious agent $S$. aureus [17-19].

In the present study we describe for the first time a largescale $(3000 \mathrm{~L})$ regulated gene expression process for the production of a heterologous protein - lysostaphin - in $L$. lactis using the NICE expression system. Furthermore, we also describe the purification of lysostaphin from the $3000-\mathrm{L}$ fermentation batches resulting in a $90 \%$ pure pharmacological intermediate that has been further purified, formulated and used in clinical phase I studies.

\section{Results}

Construction of a lysostaphin expression system in L. lactis The coding sequence of the lysostaphin gene of S. simulans biovar. Staphylolyticus, lacking its first two alanine residues [15], was cloned after PCR amplification into the NICE vector pNZ8148, resulting in plasmid pNZ1709 (see Table 1). The obtained construct was verified by nucleotide sequencing. Subsequently, the chloramphenicol-resistance cassette was exchanged for the lacF gene of L. lactis [11], leading to pNZ1710 (Fig. 1A). In this plasmid expression of the lysostaphin gene lss is under control of the nisin-inducible nisA promoter. Furthermore, this plasmid is selected by a food-grade mechanism, i.e. growth on lactose, and does not contain an antibioticresistance gene or its remnants. Lysostaphin, a 25-kD antibacterial protein, was produced in the cytoplasm of the cells. Figure 1B shows an SDS-PAGE image of the intracellular soluble protein fractions of NZ3900 (pNZ1710) before and after induction with nisin. After induction with nisin, lysostaphin is accumulated in the cell to about $10 \%$ of the soluble protein fraction, as estimated from SDSPAGE (Figure 1B). Lysostaphin was isolated, purified (see below) and its N-terminal amino acid sequence was determined to be Thr-His-Glu-His-Ser-Ala [15]. This indicates that the correct protein was produced, that no significant intracellular degradation occurred and that the N-terminal formyl-methionine residue was removed.

\section{Development of a fermentation medium and an induction scheme for lysostaphin production}

In the development of human and animal pharmaceuticals it is important that the product is guaranteed BSE (Bovine Spongiform Encephalomyelitis) agent-free. All commercially available pre-formulated media for lactococci [e.g. M17 [20] contain components of animal origin such as meat extract and are possible sources for the BSE agent. Therefore, a new medium based on hydrolysed plant protein and yeast extract was developed. The key components of that medium are an entirely plant-based 


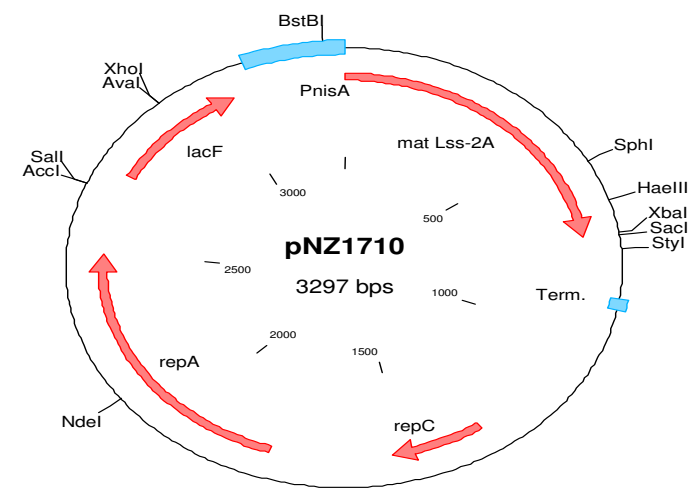

A

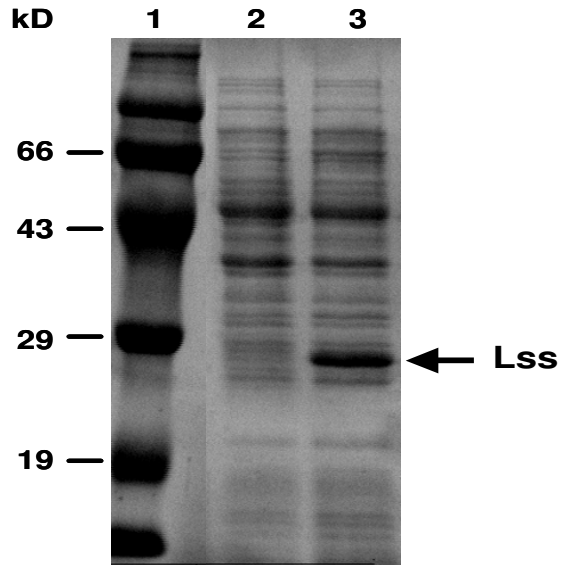

B

\section{Figure I}

Plasmid bearing the lysostaphin gene and over expression of this gene. A, plasmid construct for nisin-controlled lysostaphin production. $\mathrm{P}_{\text {nis }}$, nisin-controlled promoter; matLss-2A, coding sequence for mature lysostaphin lacking the first 2 alanine residues; Term., transcription terminator; repC and repA, replication genes; lacF, food-grade lactose selection marker. $B$, SDS-PAGE showing the intracellular production of lysostaphin upon induction with nisin. I, molecular weight marker; 2 , cell extract without nisin-induction; 3 , cell extract with induction with $10 \mathrm{ng} / \mathrm{mL}$ nisin; Lss, lysostaphin

peptone and a yeast extract that is clear in a solution of at least $1 \%$. The peptone chosen, was made from soy protein digested with the plant derived proteinase papain. Additionally, the medium contained 5\% lactose (certified BSE free) to allow unlimited growth under pH-regulated growth conditions. Finally, $\mathrm{Mg}^{2+}$ and $\mathrm{Mn}^{2+}$ were added as known growth enhancers for lactic acid bacteria [20]. For details of the composition and sterilization of the medium see Methods.

Induction of lysostaphin production was carried out at an optical density at $600 \mathrm{~nm}$ of about 1 (light path $1 \mathrm{~cm}$ ) (mid exponential growth phase) $(0.3 \mathrm{~g} / \mathrm{L}$ cell dry weight [21]) by adding nisin (Figure 2). After induction, lysostaphin production proceeded for $6-8$ hours. Figure 2 shows that upon induction, growth of the culture is severely inhibited. This is likely the result of lysostaphin accumulation in the cell that appears to have growth inhibiting properties (viable plate counts drop within 20 min after induction 3-4 orders in magnitude).

\section{Scale-up of lysostaphin production to $300 \mathrm{~L}$ and $3000 \mathrm{~L}$}

Lysostaphin production was scaled up from 1-L scale to 300-L scale and eventually 3000-L fermentations. Growth and induction conditions found at laboratory scale were directly transferred to the 300-L and 3000-L scale: Induction at an optical density $\mathrm{OD}_{600}=1$ with $10 \mathrm{ng} / \mathrm{ml}$ nisin. Details of media preparation for the larger scales are described in Methods. Figure 3 shows the growth characteristics of induced cultures of L. lactis carrying the plasmid pNZ1710 at all three scales. All three cultures behaved very similarly, despite the difference in scale of more than 3 orders of magnitude. The lysostaphin yields of the $1-\mathrm{L}$ and $3000-\mathrm{L}$ fermentations after induction were approximately $100 \mathrm{mg} / \mathrm{L}$. Four consecutive 3000-L production runs were carried out to produce raw material for 


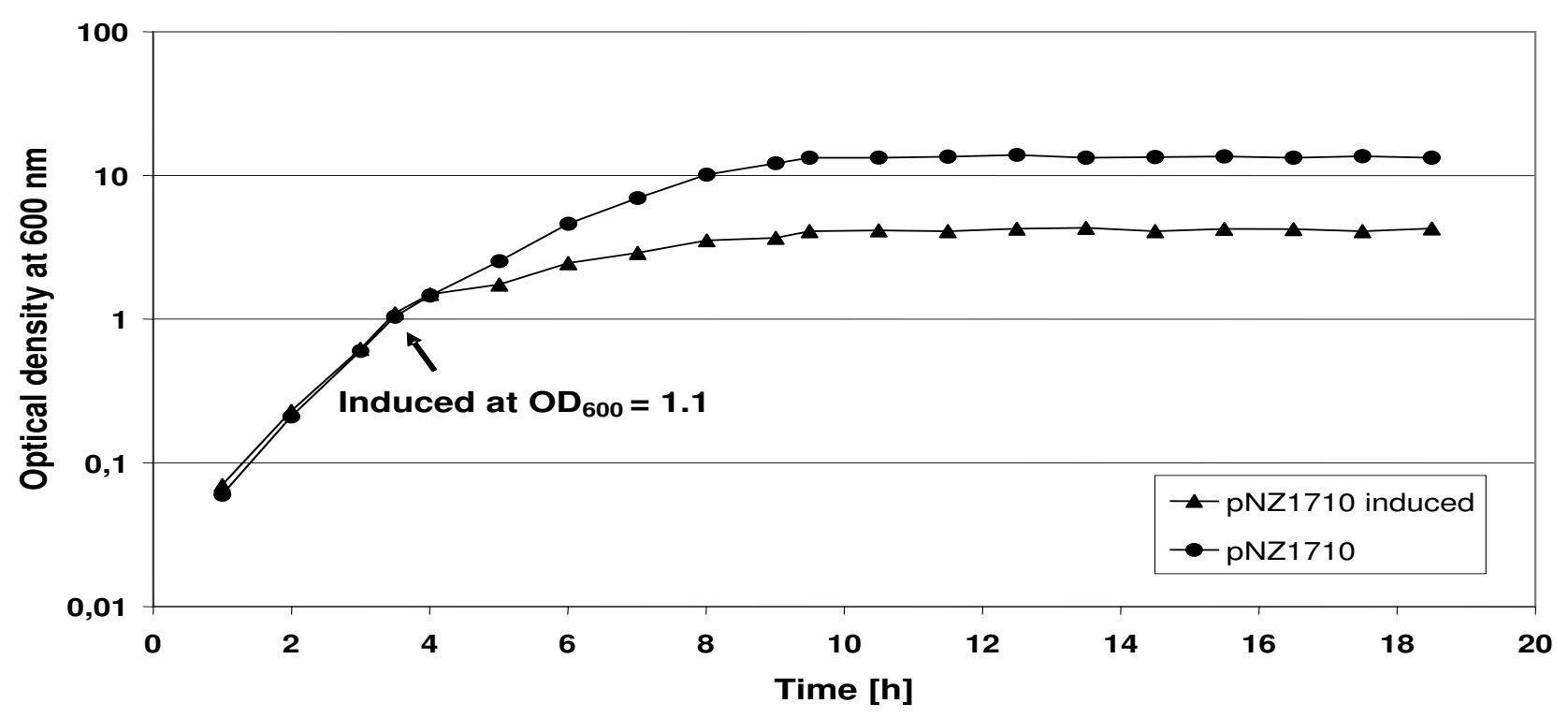

Figure 2

Growth characteristics of I-L culture. Culture at I-L scale of L. lactis NZ3900 containing the lysostaphin expression plasmid pNZI7IO with and without induction by $10 \mathrm{ng} / \mathrm{mL}$ nisin.

further down stream processing. The growth characteristics of the four fermentation runs were virtually identical. In each run approximately $300 \mathrm{~g}$ lysostaphin $(100 \mathrm{mg} / \mathrm{L})$ were produced and subsequently used as starting material for purification.

\section{Downstream processing of the 3000-L lysostaphin production batch}

A downstream processing protocol was designed for the preparation of a pharmaceutical intermediate that could be used for further purification and formulation to carry it into clinical phase I trials.

The basic operations were concentration and washing of the cells, destruction of the cells by homogenization, removal of the cell debris, and capturing of the lysostaphin by chromatography.

The fermenter content was concentrated about 20-fold by filtration (tangential flow) over a $0.8 \mu \mathrm{m}$ ceramic membrane $\left(3.8 \mathrm{~m}^{2}\right)$ and then $200 \%$ diafiltrated to remove most of the residual medium components. The retentate was subjected to continuous homogenization at 1400 bar, $80 \mathrm{~L} / \mathrm{h}$. The homogenization procedure was repeated three times to ensure complete release of the intracellular lysostaphin produced.

The cell debris was then separated from the intracellular fraction by filtration (tangential flow) over a $0.8 \mu \mathrm{m}$ ceramic membrane $\left(3.8 \mathrm{~m}^{2}\right)$. The homogenate was first concentrated to $100 \mathrm{~L}$ and then $300 \%$ diafiltrated to wash out any lysostaphin associated with the cell debris. The resulting lysostaphin-containing filtrate of about $400 \mathrm{~L}$ was stored frozen before loading onto the chromatography column.

\section{Capturing lysostaphin}

A cation-exchange chromatography capture step was selected based on the relatively alkaline isoelectric point (pH 9.5) of lysostaphin [16]. Because of superior performance, the strong exchanger SP-Sepharose FF was chosen over the weak exchanger CM-Sepharose FF. Optimum lysostaphin binding was found at $\mathrm{pH} 7.5$ in phosphate buffer. Lysostaphin was eluted using a $\mathrm{NaCl}$ step gradient 


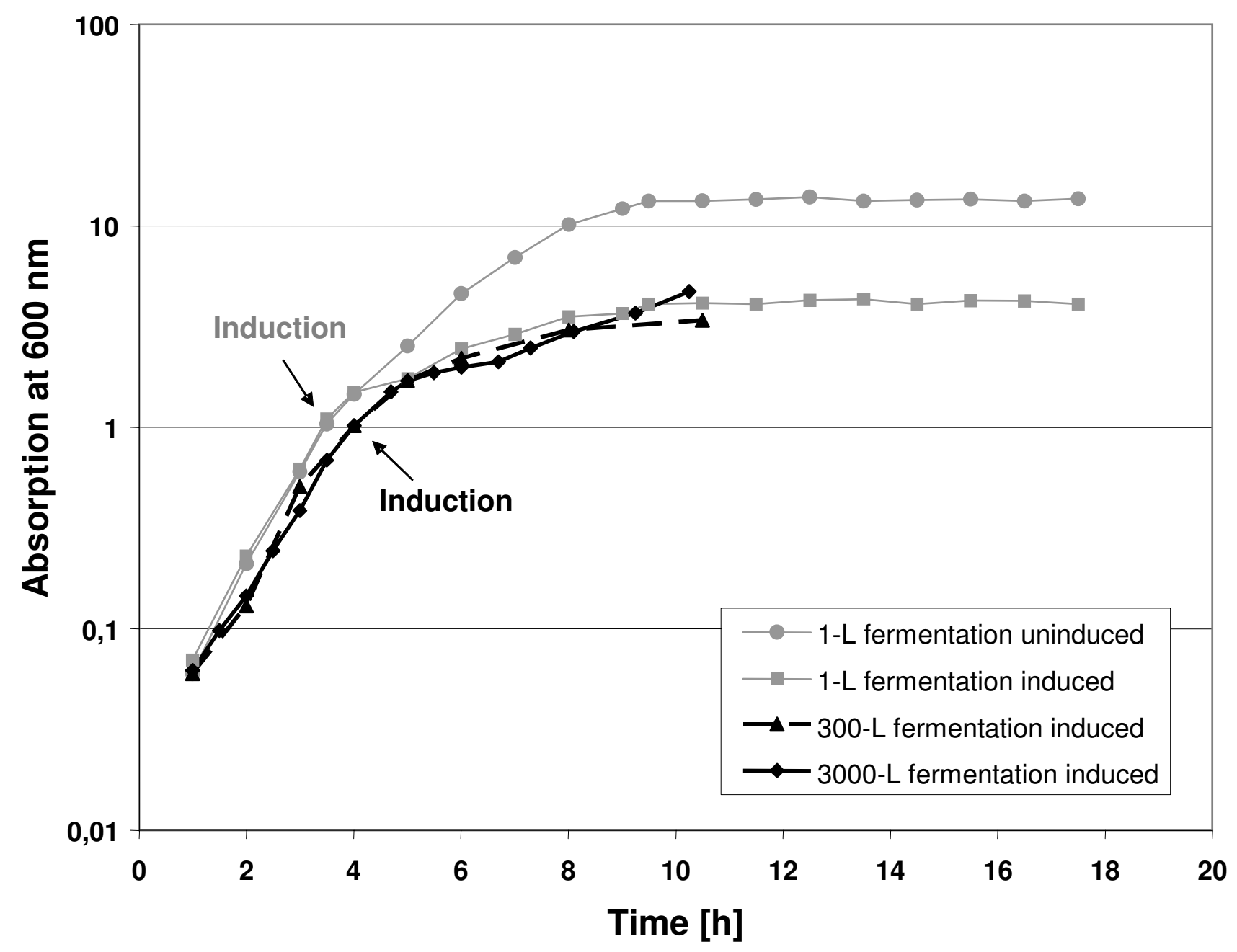

Figure 3

Comparison of growth characteristics of I-L, 300-L and 3000-L cultures. Culture of L. lactis NZ3900 containing the lysostaphin expression plasmid pNZI7I0 at I-L, 320-L and 3000-L scale with induction by $10 \mathrm{ng} / \mathrm{mL}$ nisin. As comparison, growth of an uninduced culture at I-L scale is shown.

at $0.5 \mathrm{M} \mathrm{NaCl}$ with the same $\mathrm{pH}$ and phosphate buffer concentrations (Methods) as used for loading (Figure 4A and $4 \mathrm{~B}$ show an elution profile and SDS-PAGE analysis). Since maximum binding of lysostaphin was hindered by unknown components in the cell extract, the flowthrough was re-fed to the column twice to capture more than $90 \%$ of lysostaphin from the cell extract. Finally, the eluate was diluted and all captured lysostaphin was applied to the column at once for an additional recapture step (Methods). The resulting material was ca. 90\% pure lysostaphin as determined by SDS-PAGE analysis (Methods). The lysostaphin production yield in the fermentation was about $100 \mathrm{mg} / \mathrm{l}$. Therefore about $300 \mathrm{~g}$ lysostaphin had been produced in each 3000-L fermentation run. The mean total yield of the downstream process was about $120 \mathrm{~g}$, resulting in $40 \%$ recovery of the originally produced lysostaphin.

\section{Discussion}

Nisin-regulated gene expression in Lactococcus lactis has been shown to be an effective and multifunctional tool $[2,5,7,9]$. L. lactis has numerous characteristics that make it an interesting host for industrial-scale heterologous protein production: it is $100 \%$ food grade, including plasmid selection systems, it produces no endotoxins or other toxic substances, it produces no inclusion bodies and no 
A

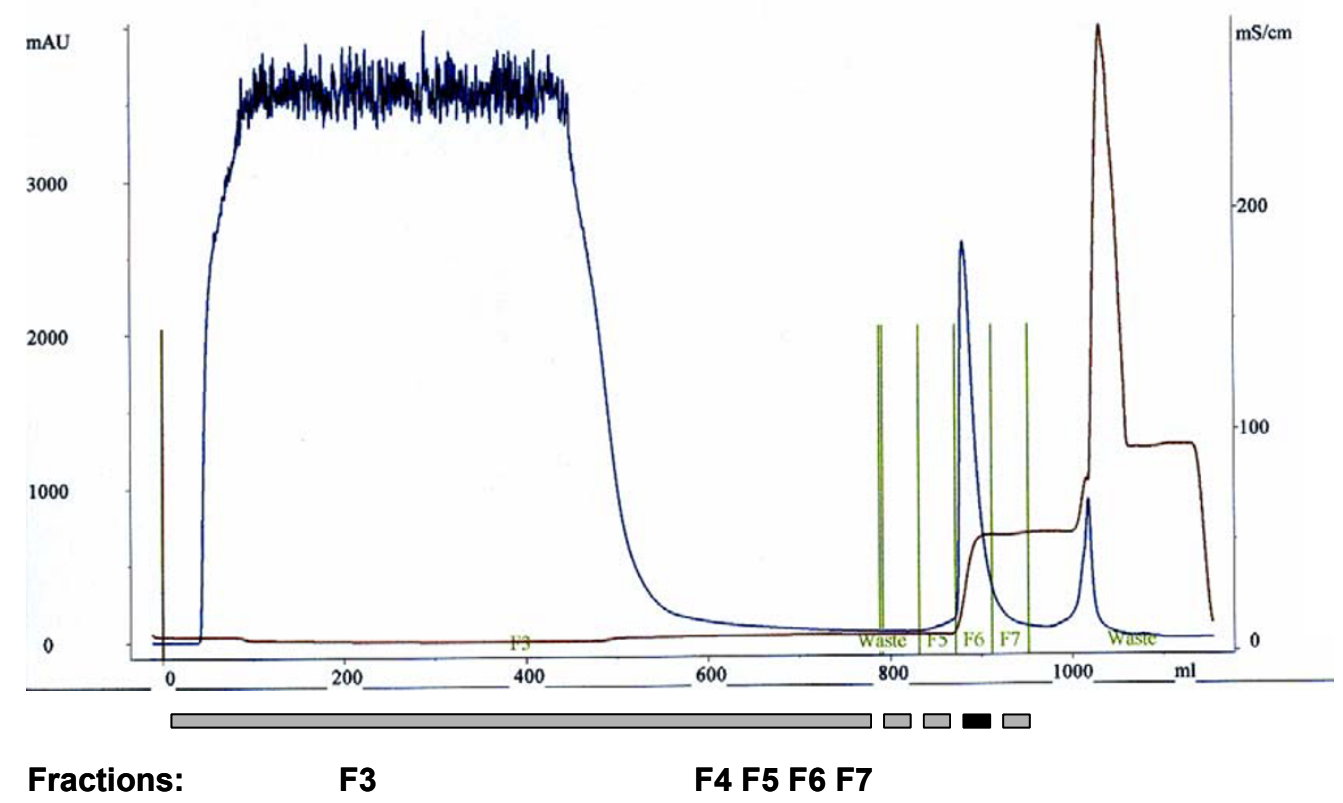

B

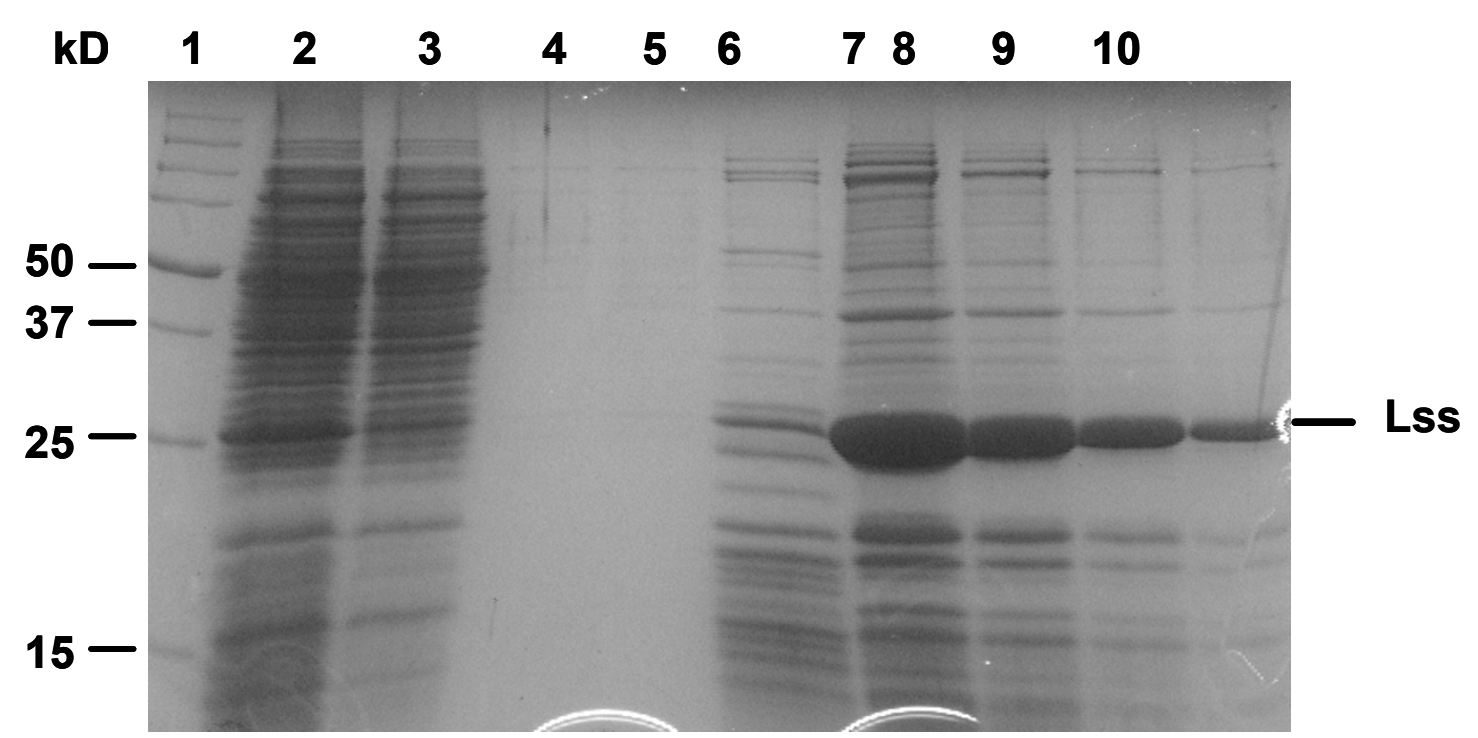

\section{Figure 4}

Purification of the overproduced lysostaphin. A, Typical chromatogram of a lysostaphin capture step. $\mathrm{NaCl}$ concentration (brown line) and absorption at $280 \mathrm{~nm}$ (blue line) are indicated. Fractions that were analysed by SDS-PAGE are indicated by grey bars underneath. The lysostaphin fraction (F6) is indicated with a black bar. B, SDS-PAGE analysis of the different fractions of the capture chromatography. I, molecular weight marker; 2, cell extract before loading; 3, flow-through fraction (F3); 4,5 and 6 , fractions F4, F5 and F7; 7, lysostaphin fraction F6;8, 9 and 10 , fraction F6 diluted $1: 2,1: 4$ and $I: 8$. 
spores, it is grown in simple non-aerated, stirred fermentations and produces no extracellular proteinases. With these characteristics, it can be used for food applications, as a source of enzymes, for metabolic transformations and for the production of biologicals. The fact that L. lactis is food grade also means that cellular components or enzymes can be used with only partial purification or directly in the crude cell extract without further purification. Despite 10 years of laboratory use of the NICE system, we are not aware of any reports that describe the step to large-scale industrial application of this tool. This paper describes the successful development and scale-up of a process for the production of a heterologous protein using lysostaphin as an example. Lysostaphin is an antibacterial protein from $S$. simulans biovar. Staphylolyticus, that has potential in topical and systemic applications for the treatment of Staphylococcus aureus infections [17-19]. Lysostaphin is a clear example for the benefits of a regulated expression system, since constitutive intracellular lysostaphin expression leads to rapid cell death. Another advantage of regulated gene expression is that the cells can be pre-grown to a certain cell density before the energetically costly production of a foreign protein is switched on.

Furthermore, a food-grade plasmid selection system based on lactose consumption has been used, making the use, detection and tracing of antibiotics unnecessary. This food-grade construct allowed the production of a pharmaceutical intermediate in a cheaper food-grade production plant rather than in a cGMP facility. Similarly, such a process could be used to make other industrially interesting intermediates such as enzymes for food and (bio)chemical applications, probiotic preparations, etc.

The process described in this paper was first developed at 1 -L scale and subsequently transferred to the 300-L and 3000-L scale. This scale-up was without problems, without specific calculations and without changes in the available equipment. L. lactis is a simple fermentative, oxygen-tolerating bacterium converting lactose or glucose into lactic acid. Therefore, no oxygen transfer is needed during the fermentation. The only condition that needs to be met is appropriate mixing of the whole culture to ensure evenly distributed nutrients and effective distribution of nisin for the induction of gene expression. One significant difference exists in the addition of nisin to the culture at different scales. At laboratory scale this addition takes a few seconds, while at 3000-L scale it takes 2 - 5 min. Despite the difference in addition times, no adverse effects on the induction process and lysostaphin production were observed.

We carried out four consecutive fermentations at the 3000-L scale. The growth of the culture in all four fermentation runs was nearly identical, as was the final yield of lysostaphin after purification (about $120 \mathrm{~g}$ per batch), indicating the biological and technical robustness of the process.

The down-stream processing shows that $L$. lactis can effectively be separated from the fermentation medium and that the cell content can be released by high-pressure continuous homogenization. In the present process three passages for complete destruction of the cells are used. Preliminary results show that two passages may be enough. The cell debris can simply be removed by a second filtration step in the same equipment that is used for the cell separation. After separation of the cell content from the debris, the product can be used as crude extract with enriched enzyme activity or different routes can be followed to further purify or enrich the active component: ultrafiltration, selective precipitation and chromatography. In the present process, lysostaphin was captured on SP-Sepharose FF in two consecutive steps. We found that an as yet unknown component in the cell extract hampered binding of lysostaphin to the resin. This obstacle was overcome by repeated loading of the flow-through to the same column. The solution of captured lysostaphin apparently lost the interfering component and could be completely bound to the resin in one recapture run. Further research is needed to identify the interfering compound and to design a process in which lysostaphin can be captured in a single run.

While $100 \mathrm{mg} / \mathrm{L}$ yield is relatively low for bulk productions, it may be acceptable for specialized productions. Careful optimization of growth and induction can lead to considerable yield increases. This was also demonstrated for lysostaphin were in a separate set of experiments lysostaphin production was optimized and a yield of 300 $\mathrm{mg} / \mathrm{L}$ was reached [22]. One of the challenges is the development of a fermentation process in which this fermentative organism can be grown to higher cell densities.

The downstream process as a whole consists only of a few steps and is thereby simple, fast and highly reproducible. After further optimization it could easily be carried out within $48 \mathrm{~h}$ after the fermentation run, limiting the whole process to one week from seed culture to product.

\section{Conclusion}

The present publication describes for the first time that it is possible to use the lactic acid bacterium L. lactis for industrial scale heterologous protein production. Furthermore, we demonstrate that the widely used nisin-controlled gene expression system NICE is fully operative at this scale. This opens the way for a food grade alternative expression system to the commonly used host E. coli. Other advantages are that L. lactis does not produce endotoxins or inclusion bodies, and does not produce spores 
and extracellular proteinases. This opens up a wide range of pharmaceutical, cosmetics, biochemical, food, and feed applications.

\section{Methods}

\section{Bacterial strains and plasmids}

Table 1 shows the strain and the plasmids used in this study. The bacteria were maintained as frozen stock at $80^{\circ} \mathrm{C}$.

\section{Growth media and cultivation conditions}

For the genetic construction work the bacteria were routinely grown in M17 medium [20] fortified with 1\% glucose or $0.5 \%$ lactose and $5 \mu \mathrm{g} / \mathrm{ml}$ chloramphenicol for selection on chloramphenicol resistance.

For 1-L, 300-L and 3000-L fermentations the following medium was used: $5 \%$ lactose (pharmaceutical-grade lactose Lactochem 207, Borculo DOMO Ingredients, Zwolle, The Netherlands), 1.5\% peptone from soy (VWR-Merck, product number 111932, Amsterdam, The Netherlands), $1 \%$ yeast extract (BioSpringer, product number 1105C0/ 180, Maisons Alfort, France), $1 \mathrm{mM} \mathrm{MgSO}_{4}$ (VWR-Merck), $0.1 \mathrm{mM} \mathrm{MnSO}_{4}$ (VWR-Merck). For the 1-L scale all ingredients were dissolved in water and the medium was sterilized for $20 \mathrm{~min}$ at $110^{\circ} \mathrm{C}$. For the 300 - and 3000-L scale all ingredients were dissolved in water and subsequently stream-sterilized (Crepaco, Bryan, Texas, U.S.A.) for $20 \mathrm{~s}$ at $140^{\circ} \mathrm{C}$ (batch-wise sterilization will cause chemical reactions in the medium that will inhibit growth of the bacteria). Bacteria were inoculated at $1 \%$ and grown at $30^{\circ} \mathrm{C}$. For 300 - and $3000-\mathrm{L}$ fermentations inoculum was prepared as follows. $2 \mathrm{~mL}$ frozen stocks were removed from $-80^{\circ} \mathrm{C}$ freezer, inoculated into 100 and $300 \mathrm{ml}$ fermentation medium, respectively, and grown under acidifying conditions as standing culture for $16 \mathrm{~h}$. For the $300-$ L fermentation, $30 \mathrm{ml}$ of this culture were inoculated into $3 \mathrm{~L}$ fermentation medium and cultivated under acidifying conditions as standing culture for $16 \mathrm{~h}$. For the 3000-L fermentation, $300 \mathrm{~mL}$ were inoculated into $30 \mathrm{~L}$ fermentation medium in a 75-L fermentor and cultivated for 16 $\mathrm{h}$ with a stirring speed of $50 \mathrm{rpm}$ under acidifying conditions.

\section{Nisin induction}

0.04\% nisin powder (Sigma-Aldrich Chemie, Zwijndrecht, The Netherlands) was dissolved in $0.05 \%$ acetic acid and precipitated proteins were removed by centrifugation. Cells were grown to an optical density at $600 \mathrm{~nm}$ of 1 (light path $1 \mathrm{~cm})(=0.3 \mathrm{~g} / \mathrm{L}$ cell dry weight [21]) at which point $10 \mathrm{ng} / \mathrm{ml}$ of nisin (final concentration) was added. Following the induction, the culture was incubated for $6-8 \mathrm{~h}$ before harvest. The 3000-L fermentations were terminated by rapid cooling to $4^{\circ} \mathrm{C}$ and stored for about $12 \mathrm{~h}$ at this temperature before further processing.

\section{Molecular techniques}

Standard genetic techniques were carried out according to Sambrook et al. [23]. SDS-PAGE was performed according to Laemmli [24]. N-terminal amino acid sequencing was outsourced (Protein Sequencing Laboratories, University of Leiden, Netherlands).

\section{Detection and quantification of lysostaphin}

Lysostaphin production was routinely monitored using SDS-PAGE. The activity of the enzyme was determined using the Staphylococcus carnosus cell wall degradation assay [15]. Lysostaphin was quantified using capillary electrophoresis as described in Mierau et al. [22]. Purity of lysostaphin was determined from scanning and analysis of SDS-PAGE gels with a PowerLookIII scanner (UMAX Systems GmbH, Düsseldorf, Gemany) and the ImageMaster software (GE Healthcare, formerly Amersham Biosciences, Rosendaal, The Netherlands).

\section{Equipment for fermentation, filtration and homogenization}

For 1-L, 30-L, 300-L, and 3000-L fermentations, stirred, temperature- and pH-regulated tank fermentors were used (1 L: Applicon fermentor with Biocontroller ADI 1030, Applicon, Frederiksberg, Denmark; 30L and 300 L: Chemap fermentors, Chemap AG, Volketswil, Switzerland; 3000 L: custom made fermentor). Stirring was carried out with a propeller blade stirrer at approximately 50 rpm, to ensure proper mixing of the base and of nisin. During the fermentation, temperature and base consumption were recorded to monitor the process. To determine the cell density of the cultures and to find the time point for induction, samples were taken at regular intervals and the OD at $600 \mathrm{~nm}$ (light path $1 \mathrm{~cm}$ ) was determined.

For microfiltration, a one-stage filtration installation was used with a Ceraver ceramic membrane of $0.8 \mu \mathrm{m}$ pore size and $3.8 \mathrm{~m}^{2}$ surface (Membralox, Pall, East Hills, New York, U.S.A.). The flow rate was approximately $330 \mathrm{~L} / \mathrm{h}$.

Concentrated cell suspensions were disintegrated using a continuous homogenization process at 1400 bar with a flow rate of about $80 \mathrm{~L} / \mathrm{h}$ (Homogenizer $10.51 \mathrm{VH}, \mathrm{APV}$, Hendrik Ido Ambacht, The Netherlands). To prevent overheating, the pressure-reduction nozzle was cooled with ice water.

\section{Chromatography}

Large-scale chromatography was carried out with a Bioprocessor (max. flow rate of $120 \mathrm{~L} / \mathrm{h}$ ) and a BPG300 column (Amersham Biosciences, Roosendaal, The Netherlands). For the separation 14.1 L Sepharose Fast Flow resin (17-0792-04, Amersham Biosciences) was used, resulting in a bed height of $20 \mathrm{~cm}$. The sample was 
prepared for chromatography by adjusting the $\mathrm{pH}$ to 7.2 with $0.4 \mathrm{M} \mathrm{NaH}_{2} \mathrm{PO}_{4} \mathrm{pH}$ 7.5. The following buffers and cleaning solutions were used: Equilibration buffer, 50 $\mathrm{mM} \mathrm{NaH}{ }_{2} \mathrm{PO}_{4} \mathrm{pH}$ 7.5; Elution buffer, $50 \mathrm{mM} \mathrm{NaH}_{2} \mathrm{PO}_{4}+$ $0.5 \mathrm{M} \mathrm{NaCl} \mathrm{pH} \mathrm{7.5;} \mathrm{Regeneration} \mathrm{buffer,} 50 \mathrm{mM}$ $\mathrm{NaH}_{2} \mathrm{PO}_{4}+1 \mathrm{M} \mathrm{NaCl} \mathrm{pH}$ 7.5; Cleaning solution, $1 \mathrm{M}$ $\mathrm{NaOH}$. A standard chromatography run was carried out as follows. The column was equilibrated with 2 volumes equilibration buffer at $120 \mathrm{~L} / \mathrm{h}$, the $\mathrm{pH}$-adjusted sample was loaded at $100 \mathrm{~L} / \mathrm{h}$, the loaded column was washed with 3 volumes equilibration buffer at $120 \mathrm{~L} / \mathrm{h}$, lysostaphin was eluted with 2 column volumes elution buffer at $120 \mathrm{~L} / \mathrm{h}$ and the column was cleaned with 1 column volume cleaning solution at $50 \mathrm{~L} / \mathrm{h}$. Finally, the column was regenerated with 2 column volumes regeneration buffer at $120 \mathrm{~L} / \mathrm{h}$. This process was repeated for all subsequent runs. Since the whole sample of about $400 \mathrm{~L}$ could not be loaded at one time (Results), it was divided into four portions of approximately $100 \mathrm{~L}$ each.

For recapture, the following buffers and solutions were used: Equilibration buffer, $12.5 \mathrm{mM} \mathrm{NaH}_{2} \mathrm{PO}_{4}+75 \mathrm{mM}$ $\mathrm{NaCl}$ pH 7.0; Elution buffer, $25 \mathrm{mM} \mathrm{NaH}_{2} \mathrm{PO}_{4}+0.25 \mathrm{M}$ $\mathrm{NaCl}$ pH 7.0, Cleaning solution and regeneration buffer were as mentioned above. For recapture, the eluate of the capture step was desalted using diafiltration and the $\mathrm{pH}$ was adjusted to $\mathrm{pH}$ 7.0. The column was equilibrated with 2 column volumes of equilibration buffer at $120 \mathrm{~L} / \mathrm{h}$, the sample was loaded at $100 \mathrm{~L} / \mathrm{h}$, the column was washed with 3 volumes equilibration buffer at $120 \mathrm{~L} / \mathrm{h}$ and the product was eluted with 2 column volumes elution buffer. Cleaning and regeneration was done as described above.

\section{Authors' contributions}

IM and JM set up and supervised the project. IM was in charge of the genetic work. ES and BB worked out and were in charge of the fermentations. PL set up and was in charge of the filtration processes. IvS and EF set up and carried out the chromatography steps.

\section{Acknowledgements}

We thank Nico Vaandrager, Johan Klok and Anne Wiersma for excellent technical assistance. Furthermore, we thank Andy Lees for critical reading of the manuscript.

\section{References}

I. Leroy F, Devuyst L: Lactic acid bacteria as functional starter cultures for the food fermentation industry. Trends in Food Science and Technology 2004, I 5:67-78.

2. Konings WN, Kok J, Kuipers OP, Poolman B: Lactic acid bacteria: the bugs of the new millennium. Current Opinion in Microbiology 2000, 3:276-282.

3. Bolotin A, Wincker P, Mauger S, Jaillon O, Malarme K, Weissenbach J, Ehrlich SD, Sorokin A: The complete genome sequence of the lactic acid bacterium Lactococcus lactis ssp. lactis ILI403. Genome Res 200I, I I:731-753.

4. Bolotin A, Ehrlich SD, Sorokin A: Studies of genomes of dairy bacteria Lactococcus lactis. Sci Aliment 2002, 22:45-53.
5. de Vos WM: Safe and sustainable systems for food-grade fermentations by genetically modified lactic acid bacteria. International Dairy Journal 1999, 9:3-10.

6. Steidler L: In situ delivery of cytokines by genetically engineered Lactococcus lactis. Antonie Van Leeuwenhoek 2002, 82:323-331.

7. Nouaille S, Ribeiro LA, Miyoshi A, Pontes D, Le Loir Y, Oliveira SC, Langella $P$, Azevedo $V$ : Heterologous protein production and delivery systems for Lactococcus lactis. Genet Mol Res 2003, 2:|02-III.

8. Blatny JM, Ertesvåg H, Nes IF, Valla S: Heterologous gene expression in Lactococcus lactis; expression of the Azotobacter vinelandii algE6 gene product displaying mannuronan C-5 epimerase activity. FEMS Microbiology Letters 2003, 227:229-235.

9. Kunji ER, Slotboom DJ, Poolman B: Lactococcus lactis as host for overproduction of functional membrane proteins. Biochimica et Biophysica Acta 2003, I6 1 0:97-108.

10. Hols P, Kleerebezem M, Schanck AN, Ferain T, Hugenholtz J, Delcour J, de Vos WM: Conversion of Lactococcus lactis from homolactic to homoalanine fermentation through metabolic engineering. Nature Biotechnology 1999, 17:588-592.

II. Platteeuw C, van Alen-Boerrigter I, van Schalkwijk S, de Vos WM: Food-grade cloning and expression system for Lactococcus lactis. Appl Environ Microbiol 1996, 62:1008-1013.

12. Kuipers OP, de Ruyter PGGA, Kleerebezem M, de Vos WM: Quorum sensing-controlled gene expression in lactic acid bacteria. Journal of Biotechnology 1998, 64: I5-21.

13. de Ruyter PG, Kuipers OP, Beerthuyzen MM, Alen-Boerrigter I, de Vos WM: Functional analysis of promoters in the nisin gene cluster of Lactococcus lactis. J Bacteriol 1996, I 78:3434-3439.

14. Hickey RM, Ross RP, Hill C: Controlled autolysis and enzyme release in a recombinant lactococcal strain expressing the metalloendopeptidase enterolysin A. Appl Environ Microbiol 2004, 70: 1744-1748.

15. Thumm G, Götz F: Studies on prolysostaphin processing and characterization of the lysostaphin immunity factor (Lif) of Staphylococcus simulans biovar staphylolyticus. Molecular Microbiology 1997, 23:125I-I265.

16. Trayer HR, Buckley CE: Molecular properties of lysostaphin, a bacteriolytic agent specific for Staphylococcus aureus. Journal of Biological Chemistry 1970, 245:4842-4846.

17. Kokai-Kun JF, Walsh SM, Chanturiya T, Mond J]: Lysostaphin cream eradicates Staphylococcus aureus nasal colonization in a cotton rat model. Antimicrob Agents Chemother 2003, 47:1589-1597.

18. Wu JA, Kusuma C, Mond JJ, Kokai-Kun JF: Lysostaphin disrupts Staphylococcus aureus and Staphylococcus epidermidis biofilms on artificial surfaces. Antimicrob Agents Chemother 2003, 47:3407-34I4.

19. von Eiff C, Kokai-Kun JF, Becker K, Peters G: In vitro activity of recombinant lysostaphin against Staphylococcus aureus isolates from anterior nares and blood. Antimicrob Agents Chemother 2003, 47:3613-3615.

20. Terzaghi BE, Sandine WE: Improved medium for lactic streptococci and their bacteriophages. Applied Microbiology 1975, 29:807-8I3.

21. Pedersen MB, Koebmann BJ, Jensen PR, Nilsson D: Increasing acidification of nonreplicating Lactococcus lactis delta-thyA mutants by incorporating ATPase activity. Appl Environ Microbiol 2002, 68:5249-5257.

22. Mierau I, Olieman C, Mond J, Smid EJ: Optimization of the Lactococcus lactis nisin-controlled gene expression system NICE for industrial applications. Microb Cell Fact 2005, 4:16.

23. Sambrook J, Fritsch EF, Maniatis T: Molecular cloning: A laboratory manual, 2nd ed. Cold Spring Harbour, Cold Spring Harbour Laboratory Press; 1989.

24. Laemmli UK: Cleavage of structural proteins during the assembly of the head of bacteriophage T4. Nature 1970, 227:680-685.

25. de Ruyter PG, Kuipers OP, de Vos WM: Controlled gene expression systems for Lactococcus lactis with the food- grade inducer nisin. Appl Environ Microbiol 1996, 62:3662-3667.

26. de Vos WM: Gene cloning and expression in lactic streptococci. FEMS Microbiology Letters 1987, 46:281-295. 